\title{
IgG4-related focal retroperitoneal fibrosis in ureter suggestive of colon cancer recurrence and resected laparoscopically: a case report
}

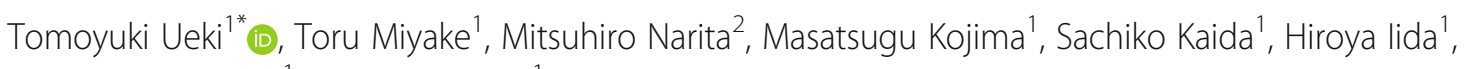
Tomoharu Shimizu ${ }^{1}$ and Masaji Tani ${ }^{1}$

\begin{abstract}
Background: Immunoglobulin G4-related disease (IgG4-RD) is a novel disease concept of unknown cause that is characterized by abundant infiltration of IgG4-positive cells, mass-forming lesions, and elevated serum IgG4 levels. The infiltration of IgG4-positive plasma cells and lymphocytes causes swelling, inflammation, fibrosis, and obliterative phlebitis in multiple organs. On the other hand, IgG4-RD occurring in the ureters has rarely been reported. To our knowledge, this is the first report of laparoscopic partial ureteral resection for lgG4-related focal retroperitoneal fibrosis in a ureter with suspected colon cancer recurrence.

Case presentation: A 72-year-old man with a history of sigmoid colon cancer visited Shiga University of Medical Science Hospital for regular follow-up in December 2019. Enhanced abdominal computed tomography revealed a mass involving the left ureter. Furthermore, fluorine-18 fluorodeoxyglucose positron emission tomography showed significant accumulation of fluorodeoxyglucose uptake in the same region. Due to the possibility of colon cancer recurrence, a laparoscopic excisional biopsy with partial ureteral resection was performed. Histologically, IgG4positive plasma cell infiltration exceeding 10 cells per high-power field and a high ratio of lgG4-positive/lgGpositive cells exceeding 40\% were observed. The postoperative serum lgG4 level was $384 \mathrm{mg} / \mathrm{dL}$. With the application of these findings to the diagnostic algorithm in the comprehensive diagnostic criteria for lgG4-RD, the mass-forming lesion was diagnosed as definitive lgG4-related focal retroperitoneal fibrosis.
\end{abstract}

Conclusions: IgG4-RD should be considered in the differential diagnosis of retroperitoneal lesions. Moreover, laparoscopic surgery may be useful for making the diagnosis in difficult-to-biopsy cases.

Keywords: IgG4-related disease, IgG4-related focal retroperitoneal fibrosis, Laparoscopic surgery, Ureter

\section{Background}

Immunoglobulin G4-related disease (IgG4-RD) is a novel systemic disease of unknown cause that is characterized by IgG4-positive plasma cell and lymphocyte infiltration histologically and elevated serum IgG4 levels. This disease, first described by Hamano et al. [1], affects

\footnotetext{
* Correspondence: ueki@belle.shiga-med.ac.jp

${ }^{1}$ Department of Surgery, Shiga University of Medical Science, Tsukinowa-cho,

Seta, Otsu-shi, Shiga 520-2192, Japan

Full list of author information is available at the end of the article
}

various organs including the salivary glands, pancreas, liver, bile duct, lungs, thyroid, kidneys, prostate, retroperitoneum, lymph nodes, and breasts. Focal retroperitoneal fibrosis, a type of IgG4-RD, is characterized by thickening of the abdominal aortic adventitia and soft tissue around the ureter [2]. On the other hand, the differential diagnosis from secondary retroperitoneal fibrosis caused by various diseases such as malignancy and infection often becomes clinically problematic because biopsy is difficult in many cases. Here, we report a case

\section{SpringerOpen}

(๑) The Author(s). 2020 Open Access This article is licensed under a Creative Commons Attribution 4.0 International License, which permits use, sharing, adaptation, distribution and reproduction in any medium or format, as long as you give appropriate credit to the original author(s) and the source, provide a link to the Creative Commons licence, and indicate if changes were made. The images or other third party material in this article are included in the article's Creative Commons licence, unless indicated otherwise in a credit line to the material. If material is not included in the article's Creative Commons licence and your intended use is not permitted by statutory regulation or exceeds the permitted use, you will need to obtain permission directly from the copyright holder. To view a copy of this licence, visit http://creativecommons.org/licenses/by/4.0/. 
of IgG4-related focal retroperitoneal fibrosis in a ureter suggestive of colon cancer recurrence that was diagnosed by laparoscopic resection.

\section{Case presentation}

A 72-year-old man visited Shiga University of Medical Science Hospital for regular follow-up of sigmoid colon cancer in December 2019. He had a medical history of undergoing an appendectomy at age 10 and laparoscopic sigmoidectomy for sigmoid colon cancer (pStage I) at age 70 . The histopathological diagnosis of the colon cancer was moderately differentiated tubular adenocarcinoma and tumor invasion to the submucosa with venous invasion. His father died of gastric cancer. Enhanced abdominal computed tomography $(\mathrm{CT})$ revealed a mass involving the left ureter that had grown slowly since the previous CT. He underwent further examinations for the diagnosis. A physical examination revealed no abdominal pain or palpable mass. Additionally, no enlarged lymph nodes were palpable in the cervical, axillary, or inguinal regions. Laboratory data included elevated lactate dehydrogenase $(239 \mathrm{U} / \mathrm{L})$, creatinine $(1.14 \mathrm{mg} / \mathrm{dL})$, and carbohydrate antigen 19-9 (41 U/mL) levels. Other serum biochemical parameters and tumor markers were within the normal ranges. Urine cytology showed no atypical cells (class II).

Enhanced abdominal CT showed a $30-\mathrm{mm}$ soft-tissue mass involving the left ureter in front of the bifurcation of the left common iliac artery but no enlarged lymph nodes, hydronephrosis, or other abnormal findings (Fig. 1). The mass had grown from $16.7 \times 10.3 \mathrm{~mm}$ to $30 \times 13.7$ $\mathrm{mm}$ in 17 months. Fluorine-18 fluorodeoxyglucose (FDG) positron emission tomography CT (PET-CT) showed significant accumulation of FDG uptake in the same region

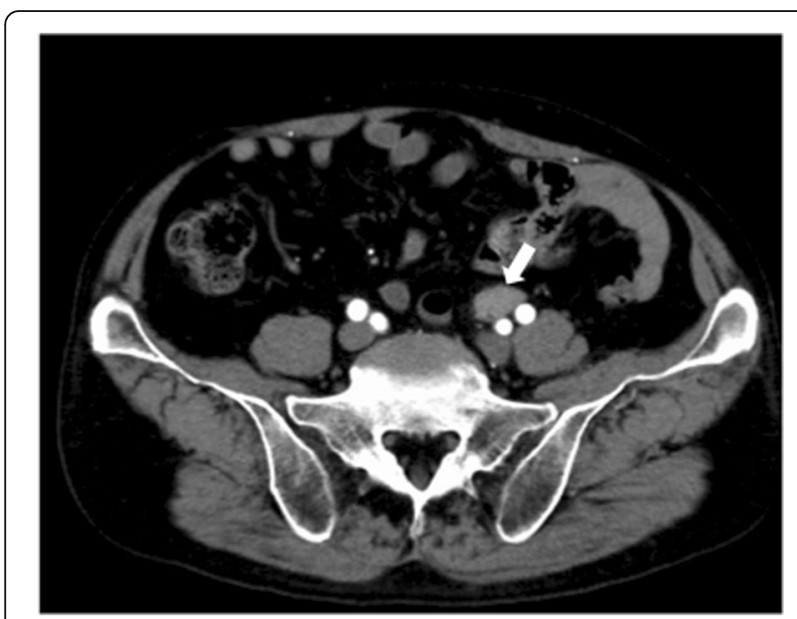

Fig. 1 Enhanced abdominal computed tomography (CT) findings. Enhanced abdominal CT showed a 30-mm soft-tissue mass involving the left ureter in front of the bifurcation of the left common iliac artery (arrow) (maximum standardized uptake value, 8.93; Fig. 2). Significant FDG uptake was not observed at any of the other sites. Ureterography and colonoscopy showed no abnormal findings.

Due to the possible lymph node recurrence or peritoneal seeding of colon cancer indicated by the slow growth and significant FDG uptake, we performed a laparoscopic excisional biopsy. Under general anesthesia, the patient was placed in the lithotomy-Trendelenburg position. First, a ureteral stent was inserted in the left ureter radiologically using a guide wire. The endoscopist stood to the upper right of the patient, the surgeon stood near the surgeon's right hand, and the assistant stood opposite the surgeon. A transumbilical skin and fascia incision was performed. The peritoneum was opened, and a 12$\mathrm{mm}$ trocar was introduced. Under pneumoperitoneum, a 12-mm trocar was placed in the lower right abdomen, and 5-mm trocars were placed in the bilateral lower and upper abdomen. We dissected and mobilized the leftsided colon using the medial-to-lateral approach in Toldt's space. After recognizing that the left ureter was involved in the mass-forming lesion in front of the bifurcation of the left common iliac artery, we mobilized the left ureter throughout the whole circumference of the massforming lesion (Fig. 3). After removing the stent, we dissected the proximal and distal ureter of the mass-forming lesion and removed the specimen from the umbilical port site. The intraoperative frozen section examination diagnosed the mass as a benign lymphoproliferative lesion. Two 4-0 Vicryl $^{\circledR}$ sutures were used to form a running anastomosis. After finishing the anastomosis of the posterior ureteral wall, a $6 \mathrm{Fr} 26-\mathrm{cm}$ double-J catheter was inserted laparoscopically. After ensuring the double-J catheter into the renal pelvis, running suture anastomosis of the anterior ureteral wall was completed. The total operative blood loss was $8 \mathrm{~mL}$, and the operative time was $321 \mathrm{~min}$. The postoperative course was uneventful, and he was discharged on postoperative day 6. After 3 months of follow-up, he had not developed any recurrent lesions or any other IgG4-RD, including autoimmune pancreatitis.

Macroscopically, an elastic and soft mass similar to a swollen lymph node with a lumen structure was detected (Fig. 4). A histological examination showed abundant infiltration of lymphocytes with lymphoid follicles around the left ureter and peripheral proliferation of collagenous fibers. Immunohistochemically, the mean IgG4-positive plasma cell count was 50 per high-power field (HPF), and the ratio of IgG4-positive/IgG-positive cells was 54\% (Fig. 5). The postoperative serum IgG4 level was $384 \mathrm{mg} /$ dL. Applying these findings to the diagnostic algorithm in the comprehensive diagnostic criteria for IgG4-RD [3], the mass-forming lesion was definitively diagnosed as IgG4related focal retroperitoneal fibrosis. 

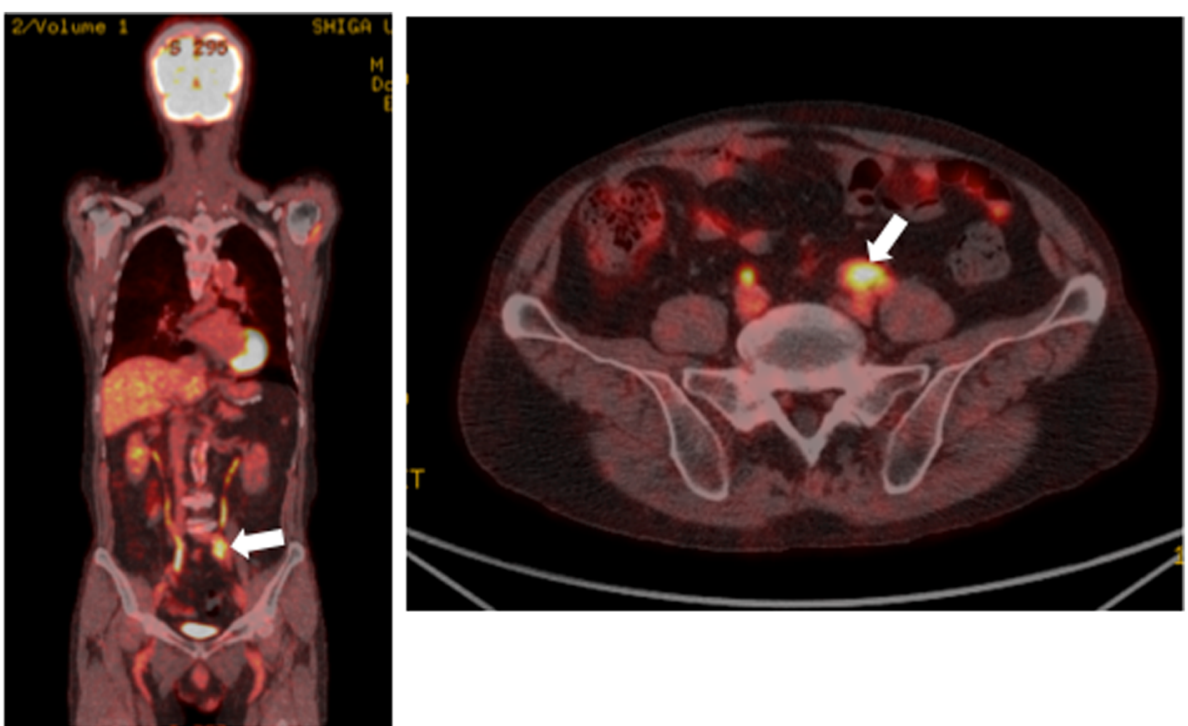

Fig. 2 Fluorine-18 fluorodeoxyglucose (FDG) positron emission tomography CT (PET-CT) findings. FDG-PET-CT showed significant accumulation of FDG uptake in the same region (maximum standardized uptake value, 8.93; arrow)

\section{Discussion}

IgG4-RD is a novel disease characterized by the abundant infiltration of IgG4-positive cells, mass-forming lesions, and elevated serum IgG4 levels. This disease was first described by Hamano et al., who reported elevated IgG4 levels in patients with autoimmune pancreatitis [1]. Clinically, IgG4-RD shows diffuse/localized swelling or mass formation in single or multiple organs, including the salivary glands, pancreas, liver, kidneys, retroperitoneum, and lymph nodes. The infiltration of IgG4positive plasma cells and lymphocytes causes swelling, inflammation, fibrosis, and obliterative phlebitis in multiple organs. IgG4-RD was predominant in elderly men, affecting about $90 \%$, particularly in the kidneys and retroperitoneum $[2,4-6]$.

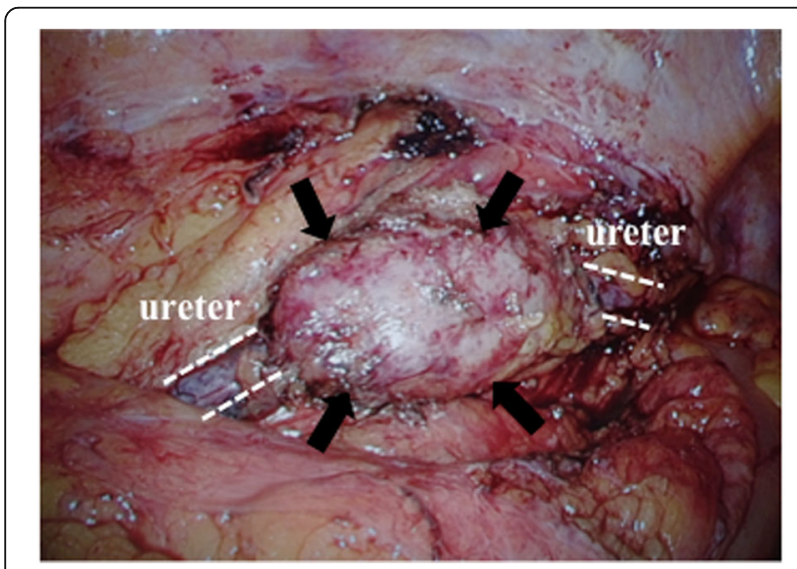

Fig. 3 Intraoperative findings. The mass around the left ureter was observed (mass; black arrow, ureter; white dotted line)
The diagnosis of IgG4-RD is based on clinical and histological features. In Japan, the Ministry of Health, Labour and Welfare released the Comprehensive Diagnostic Criteria for IgG4-RD in 2011 [3]. In our case, the enhanced abdominal CT showed a localized swollen mass around the left ureter and the serum IgG4 level was over $135 \mathrm{mg} / \mathrm{dL}$. Furthermore, the histological examination showed abundant lymphocytic and plasmacytic infiltration with an increased number of IgG4positive plasma cells ( $>10 / \mathrm{HPF}$ and a $>40 \%$ ratio of IgG4-positive/IgG-positive cells). Based on these features, our case was diagnosed as IgG4-related focal retroperitoneal fibrosis.

On the other hand, secondary retroperitoneal fibrosis caused by drugs, radiation, bleeding, malignancy, and infection had to be considered as a differential disease in the preoperative diagnosis. In our case, these factors were excluded based on symptoms, medical history, and examination findings. The ureteral tumor was also excluded because there were no abnormal findings on the preoperative ureterography or malignant cells in the urine cytology. However, in our case, it was difficult to completely distinguish malignant tumors from benign lesions. No specific symptoms associated with the massforming lesion were observed, but colon cancer recurrence was possible considering the slow growth and significant FDG uptake. Therefore, we performed laparoscopic resection to enable the diagnosis and treatment. Retrospectively, serum IgG4 level should be measured before the preoperative diagnosis since IgG4-RD is a differential disease. Although performing a biopsy for the definitive diagnosis is often difficult when retroperitoneal fibrosis is close to 

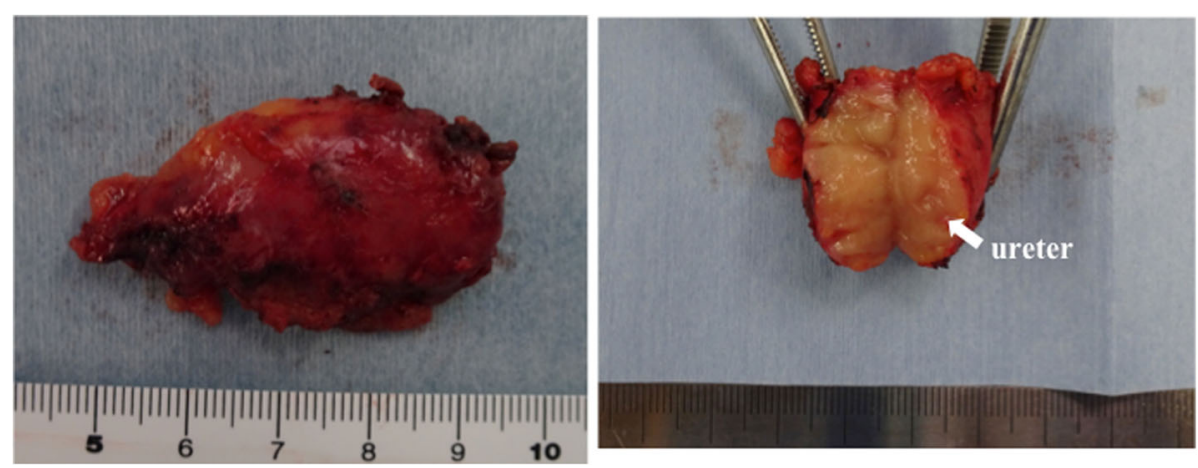

Fig. 4 Macroscopic findings of the resected specimen. An elastic and soft mass similar to a swollen lymph node with a lumen structure (ureter) was detected (arrow)

various organs, laparoscopic surgery enabled minimally invasive excisional biopsy in this case.

IgG4-RD treatment remains controversial. Yoshino et al. reported that corticosteroid therapy was effective for retroperitoneal fibrosis with elevated serum IgG4 level, and clinical symptoms improved as serum IgG4 level decreased [7]. However, there are no definitive criteria for corticosteroid dose or duration, and follow-up without treatment is often provided in asymptomatic cases [8]. In our case, the patient received no corticosteroid therapy after surgery because he was asymptomatic and concerned about the side effects of long-term corticosteroid use.

On the other hand, Wallace et al. reported that a history of malignancy might be associated with subsequent IgG4-RD development [9]. One possibility is that treatments for malignancy, including chemotherapy, cause immunodeficiency and lead to IgG4-RD. In our case, due to no postoperative adjuvant chemotherapy and a long period after sigmoidectomy, we thought that the sigmoid colon cancer was not significantly associated with the mass-forming lesion. The histopathological examination of the sigmoid colon cancer performed retrospectively revealed IgG4-positive plasma cells (> 10/ HPF). However, the significance is controversial, because IgG4-positive cells were similarly detected in the normal mucosa.

Moreover, Hamano et al. reported the probability of developing IgG4-RD including autoimmune pancreatitis during the clinical course of IgG4-related retroperitoneal fibrosis [1]. Our patient had no specific symptoms associated with autoimmune pancreatitis, such as back pain, general malaise, body weight loss, or jaundice. Furthermore, on enhanced abdominal CT, no pancreatic enlargement or main pancreatic duct narrowing was observed. However, for the above-mentioned reason, he required continual monitoring for the occurrence of other organ lesions.

To our knowledge, the published literature concerning IgG4-RD occurring in ureters is rare, with only 13 cases found globally in our survey. All cases including ours are summarized in Table 1 [10-18], which shows that 11 (78.6\%) were men and 3 (21.4\%) were women. The median patient age was 74 years (range, 39-84 years). The a.

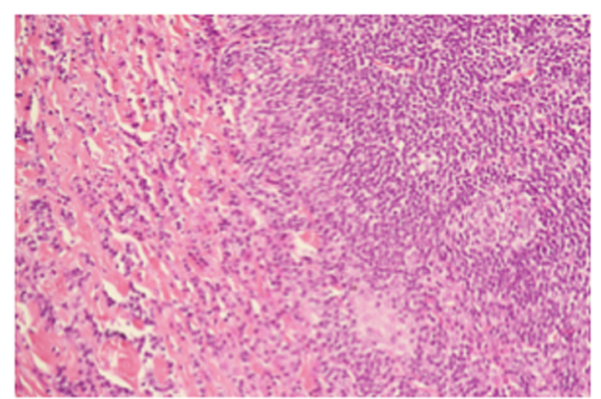

b.

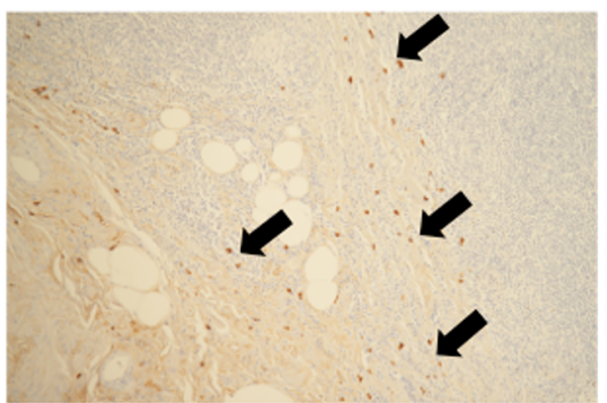

Fig. 5 Histopathological findings. a Hematoxylin and eosin staining showed abundant infiltration of lymphocytes with lymphoid follicles around the left ureter and peripheral proliferation of collagenous fibers ( $\times 200)$. b Immunohistochemical staining showed that the mean IgG4-positive plasma cell count was 50 per high-power field, and the ratio of IgG4-positive/lgG-positive cells was 54\% (IgG4, immunoperoxidase, × 100; arrow) 
Table 1 Summary of IgG4-related disease in the ureter

\begin{tabular}{|c|c|c|c|c|c|c|c|c|c|c|}
\hline Case & Author & Age & Sex & Clinical diagnosis & $\operatorname{lgG} 4$ (mg/dL) & Hydronephrosis & AIP & Operation & Laparoscopy & Steroid \\
\hline 1 & Hamano et al. [10] & 60 & M & Cancer & 265 & + & + & Nephroureterectomy & - & $40 \mathrm{mg}$ \\
\hline 2 & Hamano et al. [10] & 74 & M & Cancer & 965 & + & + & Partial ureteral resection & - & $40 \mathrm{mg}$ \\
\hline 3 & Kamisawa et al. [11] & 75 & M & Cancer & 240 & + & + & Partial ureteral resection & - & Not described \\
\hline 4 & Bessho et al. [12] & 74 & M & Cancer & 412 & + & - & Nephroureterectomy & - & Not described \\
\hline 5 & Kim et al. [13] & 45 & M & Cancer & - & - & - & Nephroureterectomy & - & - \\
\hline 6 & Kim et al. [13] & 47 & M & Cancer & 855 & + & - & Partial ureteral resection & - & - \\
\hline 7 & Kim et al. [13] & 84 & $\mathrm{~F}$ & Cancer & - & + & - & Nephroureterectomy & - & - \\
\hline 8 & Abe et al. [14] & 39 & M & Cancer & 233 & + & - & Partial ureteral resection & - & Not described \\
\hline 9 & Nomura et al. [15] & 79 & $\mathrm{~F}$ & Cancer & 206 & + & - & Nephroureterectomy & + & - \\
\hline 10 & Marand et al. [16] & 77 & M & Cancer & - & - & - & Partial ureteral resection & - & Not described \\
\hline 11 & Marand et al. [16] & 82 & $\mathrm{~F}$ & Cancer & - & + & - & Partial ureteral resection & - & Not described \\
\hline 12 & Lei WH et al. [17] & 66 & M & Cancer & 913 & + & - & Nephroureterectomy & + & $60 \mathrm{mg}$ \\
\hline 13 & Zhong W et al. [18] & 64 & M & Cancer & - & + & - & Nephroureterectomy & - & Not described \\
\hline 14 & Our case & 72 & M & Cancer & 384 & - & - & Partial ureteral resection & + & - \\
\hline
\end{tabular}

median serum IgG4 level was $384 \mathrm{mg} / \mathrm{dL}$ (range, 206$965)$ in 9 cases. All cases were over the standard value. A nephroureterectomy was performed in 7 cases versus a partial ureteral resection in 7 cases. Three cases were treated laparoscopically. Two patients underwent laparoscopic nephroureterectomy, while our patient underwent laparoscopic partial ureteral resection. This is the first report of laparoscopic partial ureteral resection for IgG4-related focal retroperitoneal fibrosis in a ureter with suspected colon cancer recurrence.

\section{Conclusion}

Here, we reported a case of IgG4-related focal retroperitoneal fibrosis in a ureter with suspected colon cancer recurrence that was resected by laparoscopic surgery. IgG4-RD should be considered in the differential diagnosis of retroperitoneal lesions. Moreover, laparoscopic resection could be useful for enabling the diagnosis of difficult-to-biopsy cases.

\section{Abbreviations}

AIP: Autoimmune pancreatitis; CT: Computed tomography; FDG: Fluorine-18 fluorodeoxyglucose; HPF: High-power field; IgG4-RD: Immunoglobulin G4related disease; PET-CT: Positron emission tomography $C T$

\section{Acknowledgements}

None

\section{Authors' contributions}

All authors have read and approved the final manuscript.

\section{Funding}

Not applicable

\section{Availability of data and materials}

Not applicable

Ethics approval and consent to participate Not applicable
Consent for publication

Not applicable

\section{Competing interests}

The authors declare that they have no competing interests.

\section{Author details}

${ }^{1}$ Department of Surgery, Shiga University of Medical Science, Tsukinowa-cho, Seta, Otsu-shi, Shiga 520-2192, Japan. ${ }^{2}$ Department of Urology, Shiga University of Medical Science, Tsukinowa-cho, Seta, Otsu-shi, Shiga 520-2192, Japan.

Received: 25 June 2020 Accepted: 27 July 2020

Published online: 03 August 2020

\section{References}

1. Hamano H, Kawa S, Horiuchi A, Unno H, Furuya N, Akamatsu R, et al. High serum lgG4 concentrations in patients with sclerosing pancreatitis. N Engl J Med. 2001;344:732-8.

2. Zen Y, Onodera M, Inoue D, Hosaka N, Kuriki K, Nakanuma Y, et al. Retroperitoneal fibrosis: a clinicopathologic study with respect to immunoglobulin G4. Am J Surg Pathol. 2009:33:1833-9.

3. Okazaki K, Kawa S, Kamisawa T, Umehara H, Masaki Y, Kawano M, et al. Comprehensive diagnostic criteria for lgG4-related disease (lgG4-RD) 2011. J Jpn Soc Intern Med. 2012;101:795-804.

4. Frulloni L, Lunardi C, Simone R, Vantini I, Corrocher R, Puccetti A, et al. Identification of a novel antibody associated with autoimmune pancreatitis. N Engl J Med. 2009;361:2135-42.

5. Raina A, Yadav D, Krasinskas AM, Sanders M, Whitcomb DC, Slivka A, et al. Evaluation and management of autoimmune pancreatitis: experience at a large US center. Am J Gastroenterol. 2009;1004:2295-306.

6. Raissian Y, Nasr SH, Larsen CP, Sethi S, Fidler ME, Cornell LD, et al. Diagnosis of lgG4-related tubulointerstitial nephritis. J Am Soc Nephrol. 2011;22:1343-52.

7. Yoshino T, Moriyama H, Fukushima M, Sanda N. A case of IgG4-related retroperitoneal fibrosis mimicking renal pelvic cancer. Urol Int. 2013;90:365-8.

8. Yasuda $Y$, Iwai A, Inadome $Y$, Okuno T. Three cases of IgG4-rlated focal retroperitoneal fibrosis. Jpn J Urol. 2014;105:56-61.

9. Wallace ZS, Wallace CJ, Lu N, Choi HK, Stone JH. Association of IgG4-related disease with history of malignancy. Arthritis Rheumatol. 2016;68:2283-9.

10. Hamano H, Kawa S, Ochi Y, Nakazawa K, Shimojo H, Kiyosawa K, et al. Hydronephrosis associated with retroperitoneal fibrosis and sclerosing pancreatitis. Lancet. 2002:359:1403-4.

11. Kamisawa T, Chen PY, Tu Y, Nakajima H, Egawa N. Autoimmune pancreatitis metachronously associated with retroperitoneal fibrosis with lgG4-positive plasma cell infiltration. World J Gastroenterol. 2006;12:2955-7. 
12. Bessho E, Maeyama R, Taoka Y, Ao T, Motoori T. A case of IgG4-related focal retroperitoneal fibrosis. Rinsho Hinyokika. 2010;64:337-40.

13. Kim SA, Lee SR, Huh J, Shen SS, Ro JY. IgG4-assosiated inflammatory pseudoutumor of ureter: clinicapathologic and immunestochemical study of 3 cases. Hum Pathol. 2011;42:1178-84.

14. Abe H, Morikawa T, Araki A, Nakatsu H, Fukayama M, Suzuki Y, et al. IgG4related periureteral fibrosis presenting as a unilateral ureteral mass. Pathol Res Pract. 2011;207:712-4.

15. Nomura H, Kinjo T, Oida T, Yoneda K, Tsujimoto M. IgG4-related idiopathic segmental ureteritis which was difficult to distinguish from ureteral cancer: a case report. Hinyokika Kiyo. 2013;59:167-70.

16. Marand A, D'Ambrosio G, Catanzaro F, La Rosa S, Sessa F. IgG4-related disease of the ureter: report of two cases and review of the literature. Virchow Arch. 2013;462:673-8.

17. Lei WH, Xin J, Shao CX, Zhu CY, Wu CF, Jin L, et al. IgG4-related kidney disease mimicking malignant ureter tumor: case report and literature review. Medicine. 2016;95:e2550.

18. Zhong W, Kam J, Beattie K, Yuminaga Y, Ferguson R, Ko R. A rare case of ureteral lgG4 disease masquerading as urothelial carcinoma. Urology. 2018; 118:e1-2.

\section{Publisher's Note}

Springer Nature remains neutral with regard to jurisdictional claims in published maps and institutional affiliations.

\section{Submit your manuscript to a SpringerOpen ${ }^{\circ}$ journal and benefit from:}

- Convenient online submission

- Rigorous peer review

- Open access: articles freely available online

- High visibility within the field

- Retaining the copyright to your article

Submit your next manuscript at $\boldsymbol{\nabla}$ springeropen.com 